\title{
Mitigation of overvoltage due to high penetration of solar photovoltaics using smart inverters volt/var control
}

\author{
Dilini Almeida ${ }^{1}$, Jagadeesh Pasupuleti ${ }^{2}$, Janaka Ekanayake ${ }^{3}$, Eshan Karunarathne ${ }^{4}$ \\ ${ }^{1,2,4}$ Institute of Sustainable Energy, Universiti Tenaga Nasional (UNITEN), Malaysia \\ ${ }^{3}$ Department of Electrical and Electronic Engineering, University of Peradeniya, Sri Lanka
}

\begin{tabular}{l}
\hline Article Info \\
\hline Article history: \\
Received Feb 1, 2020 \\
Revised Mar 22, 2020 \\
Accepted Apr 13, 2020 \\
\hline
\end{tabular}

Keywords:

High PV penetration

LV distribution network

Reactive power capability

Smart PV inverter

Volt/var control

\begin{abstract}
The modern photovoltaic (PV) inverters are embedded with smart control capabilities such as Volt/Var and Volt/Watt functions to mitigate overvoltage issues. The Volt/Var control has gained a significant attention in regulating grid voltage through reactive power compensation. However, the reactive power capability of a PV inverter is limited during peak irradiance and could be improved by curtailing the active power generation and by oversizing the PV inverter. This paper analyzes the performance of Volt/Var function of smart PV inverters in mitigating overvoltage issues due to high PV integration and thus increasing the hosting capacity of low voltage distribution networks (LVDNs). The study is conducted on a real Malaysian LVDN considering two different Volt/Var set points under different PV penetration levels. Results demonstrate that the oversized smart PV inverter could enhance the Volt/Var functionality by increasing its reactive power capability than a typical smart PV inverter. Further it reveals that adaptation of sensitive Volt/Var set points with shorter deadbands increase the PV hosting capacity of LVDNs.
\end{abstract}

Copyright $(2020$ Institute of Advanced Engineering and Science. All rights reserved.

\section{Corresponding Author:}

Dilini Almeida,

Institute of Sustainable Energy,

Universiti Tenaga Nasional (UNITEN),

Jalan IKRAM-UNITEN, 43000 Kajang, Selangor, Malaysia.

Email: dilinialmeida2@gmail.com

\section{INTRODUCTION}

Over recent years, solar power generation has shown a rapid growth compared to the other Distributed Energy Resources (DERs). The declining cost of PV modules and incentives set up in many countries around the world have aided the growth of solar PV to emerge as one of the most widely adopted DER in LVDNs. However, the increased influx of solar PV penetration leads to new technical challenges $[1,2]$ to the Distribution Network Operators (DNO), who are responsible in maintaining the power quality of LVDNs. Voltage rise, voltage flicker and unbalances, thermal overloads, and higher levels of harmonics are some of the technical issues caused due to high integration of solar PV to LVDNs. Voltage rise has been identified as one of the worst consequences of high solar PV penetration which could substantially limit the number of PV systems connecting to the LVDN. The peak generation and low demand conditions could significantly increase the reverse power flow resulting voltage rise at the end of the feeder [3, 4]. As can be seen in literature, a reasonable number of studies have been published addressing the voltage rise issues and feasible solutions for mitigation.

Grid reinforcement, integration of On-Load Tap Changers (OLTC) [5-7], Line Voltage Regulators (LVR), Static VAR Compensators (SVC), Static Synchronous Compensators (STATCOM) [8], capacitor banks [9] and large-scale Battery Energy Storage Systems (BESS) [10, 11] are some of the voltage regulation strategies implemented by DNOs. However, these approaches lead to costly investments and require a 
significant amount of infrastructure upgrades and maintenances to secure their efficiency. As a result, several cost-effective techniques have been proposed for controlling the grid connected PV inverter to mitigate the technical impacts associated with high integration of solar PV to LVDNs. Traditionally, the PV systems are installed with standard inverters, designed to operate with a unity power factor (only generate active power). In compliance with the revised IEEE Standard for Interconnection and Interoperability of Distributed Energy Resources with Associated Electric Power Systems Interfaces (IEEE 1547 standard) [12], PV inverters are permitted to actively control the voltage at the point of common coupling (PCC) by compensating reactive power locally. Reactive power compensation and active power management of PV inverters are two control strategies that could be adopted to maintain the terminal voltages within permissible voltage limits. The active power curtailment could be utilized to mitigate over voltage issues by reducing the amount of real power injected by the PV inverter [13]. In [14], a droop based active power curtailment technique has been proposed to overcome voltage rise in LV radial distribution feeders. Even though this method is efficient in voltage reduction, it limits the active power generation leading to loss of revenue for PV system owners. As a result, the reactive power compensation has gained a significant attention in managing the grid voltage through reactive power absorption (during overvoltage) or injection (during undervoltage). Recently, many interesting studies have been carried out, to examine the utilization of reactive power capability of PV inverters in mitigating the potential impacts induced due to high integration of solar PV to LVDNs. In reference [15], the authors have used the reactive power support of PV inverters in improving network's PV hosting capacity by mitigating voltage violations. The reactive power control strategies available in the PV inverter for voltage regulation are compared in [16]. In [17], the standard reactive power strategies of PV inverters are reviewed and a modified method is proposed to increase the PV penetration of LVDNs.

In order to manage overvoltage issues and to accommodate higher PV capacity, the modern PV inverters are embedded with smart control capabilities such as Volt/Var and Volt/Watt functions. Today, the Volt/Var control has become prominent in regulating voltage, utilizing the reactive power capability of PV inverter instead of curtailing active power generation [18-24]. However, most of these studies assume that PV inverter ratings are sufficiently high to support the peak active power generation and reactive power capacity required for the Volt/Var control. The PV inverters are typically sized to suit the rating of the PV panels and active power generation is prioritized. Therefore, the reactive power capability of PV inverter is limited during high active power generation (peak irradiance), where reactive power absorption is essential to manage over voltages. In order to provide reactive power support during high active power generation, there must be spare capacity in the inverter. Oversizing and limiting the active power output of the inverter could be adopted to ensure spare inverter capacity. However, the active power curtailment is an economic loss to the PV owners and oversizing the inverter adds an extra cost to the installation. In [25], the authors have reported that oversizing the PV inverter is economically efficient than active power curtailment. Therefore, an oversized PV inverter could be utilized to mitigate overvoltage issues due to high integration of solar PV to LVDNs.

This study investigates the smart PV inverter Volt/Var control in mitigating voltage violations due to high integration of solar PV and increasing the PV hosting capacity of LVDNs. A comprehensive analysis is conducted on a real Malaysian LVDN considering two different Volt/Var set points under different PV penetration levels. Moreover, the practical limitation of Volt/Var control (due insufficient inverter capacity) to support reactive power capability during peak irradiance periods is also addressed.

\section{RESEARCH METHOD}

\subsection{Volt/Var control of smart PV inverters}

The Volt/Var functionality of smart PV inverter is used to maintain the terminal voltage of PV systems within voltage statutory limits. This control approach allows the inverter to monitor the terminal voltage and provide a custom var response determined by the voltage at PCC, the available reactive power capability and the predefined Volt/Var set points by the utility. The Volt/Var control follows a piece-wise function as shown in Figure 1. When the voltage exceeds the pre-defined upper level (V4), as defined by the Volt/Var curve, reactive power is absorbed and when the voltage falls below the pre-defined lower level (V3), reactive power is injected to the grid to boost voltage back to normal levels [26]. The Volt/Var functionality depends on the available reactive power capability of the inverter, $Q_{i n v}^{\max }$ as described in (1).

$$
Q_{i n v}^{\max }(t)=\sqrt{S_{i n v}^{2}-P_{i n v}^{2}(t)}
$$

where, $S_{i n v}$ is the apparent power rating of the inverter and $P_{i n v}$ is the real power generation. 
The active and reactive power (P-Q) capability curve of a typical PV inverter is shown in Figure 2(a). The operating range of the inverter is represented by a semi-circle with radius $S_{i n v}$ in the P-Q space. The maximum real power generation (at unity power factor, where $S_{i n v}=P_{i n v}^{\max }$ ) is represented by the dotted line and the projections down to Q-axis defines the reactive power limit of the inverter. As shown in the figure, the reactive power capability is influenced by the active power generation. The inverter is not able to provide reactive power support during peak irradiance $\left(P_{i n v}=P_{i n v}^{\max }\right)$, where reactive power absorption is essential to manage over voltages. To overwhelm the aforementioned limitation, PV inverters could be overrated to provide reactive power support even when delivering full active power generation (Figure 2(b)).

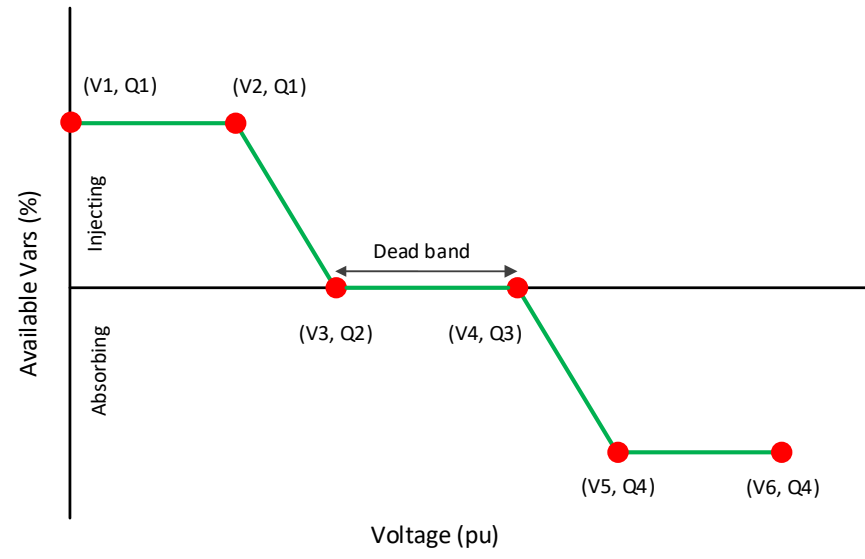

Figure 1. Volt/var curve

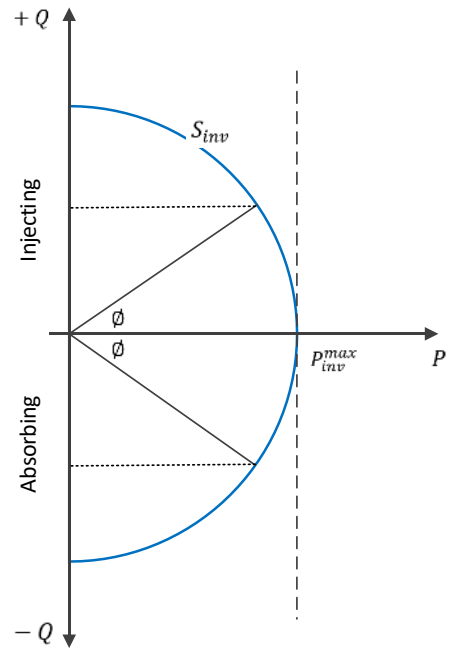

(a)

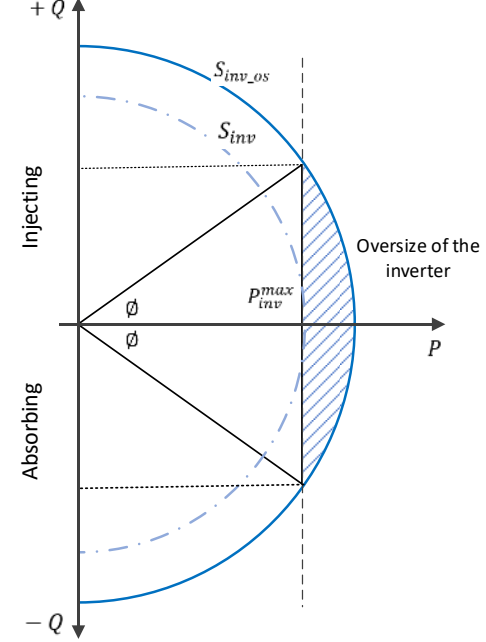

(b)

Figure 2. PV inverter capability curve, (a) Typical inverter, (b) Oversized inverter

\subsection{Methodology}

A comprehensive analysis is carried out to investigate the performance of the Volt/Var control embedded in smart PV inverters in mitigating over voltages due to high integration of solar PV. In addition, the pragmatic deficiency of Volt/Var control in reactive power absorption during peak irradiance periods is also explored. Two different Volt/Var set points (curves) are analyzed considering different PV penetration levels using two types of inverters: a 'typical' inverter with a size equal to the panel rating and an 'oversized' inverter with a size $10 \%$ higher than the panel rating. The reactive power capability of each inverter type and their suitability in voltage regulation are analyzed. In this study, the PV penetration level is defined in (2) as the ratio between peak PV power and peak load. 
$P V$ penetration $=\frac{\text { peak } P V \text { power }}{\text { peak load }} \times 100 \%$

The customers with voltage issues is selected as the performance metric to appraise the performance of Volt/Var control. According to the Malaysian Electric utility, Tenaga Nasional Berhad (TNB), the statutory tolerance limits for voltage variation should be between $+10 \%$ and $-6 \%(1.1$ and 0.94 p.u.). The daily voltage profiles of all customers are analyzed to detect the customers who do not compliance with above voltage limits. The Open Distribution System Simulator (OpenDSS) and MATLAB software packages are used to perform the time series, three-phase power flow simulations.

\subsection{Case study}

A real Malaysian residential network with a $1 \mathrm{MVA}, 11 \mathrm{kV} / 433 \mathrm{~V}$ distribution transformer was used to scrutinize the functionality of smart inverters' Volt/Var control. The single line diagram of the network is shown in Figure 3. The network consists of four feeders and serves a total number of 124 customers via a three-phase connection. The peak load demand of the network was assumed to be $620 \mathrm{~kW}$, with an average peak load of $5 \mathrm{~kW}$ per customer. The normalized PV profile and residential load profile used in the study are shown in Figure 4.

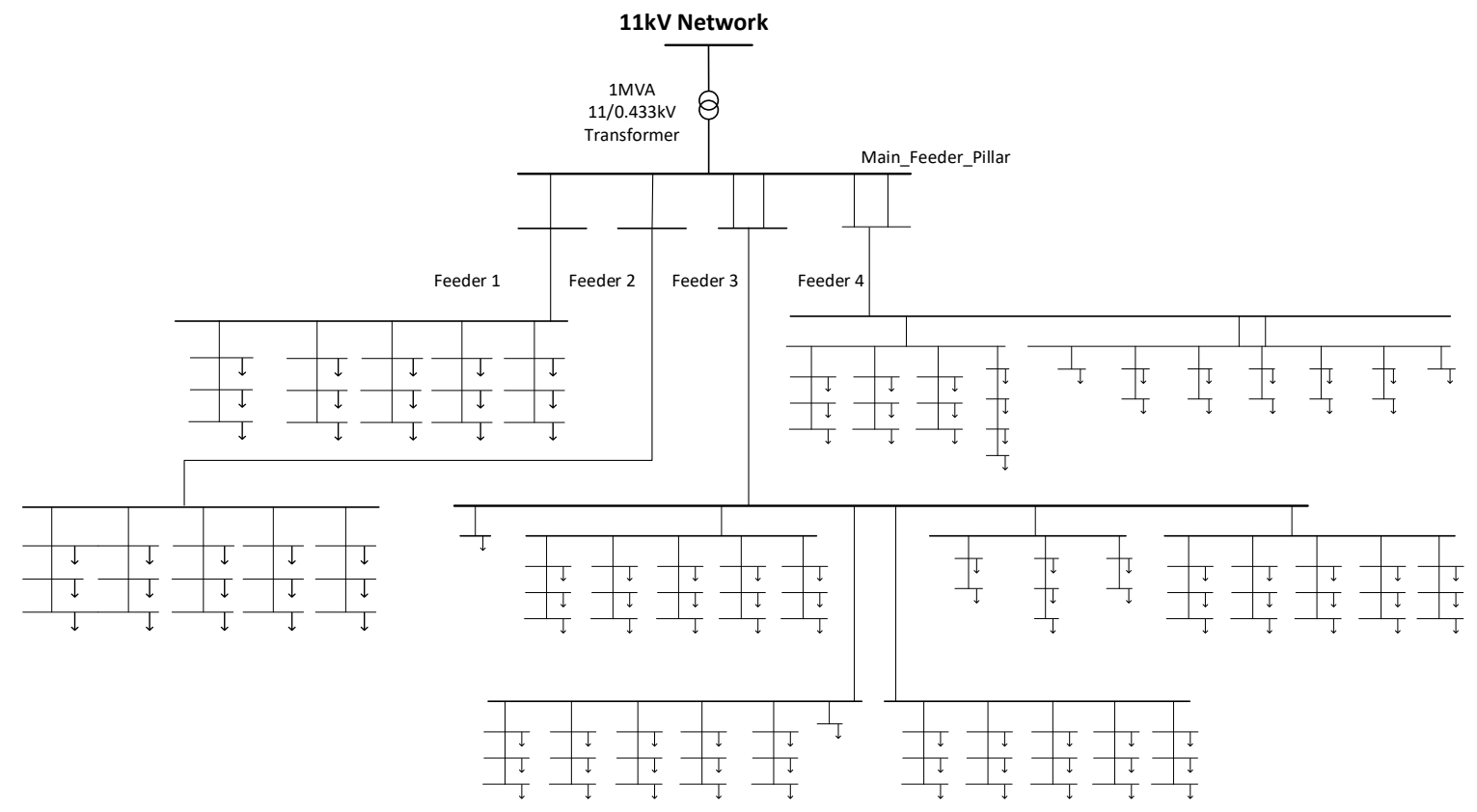

Figure 3. Single line diagram of the network

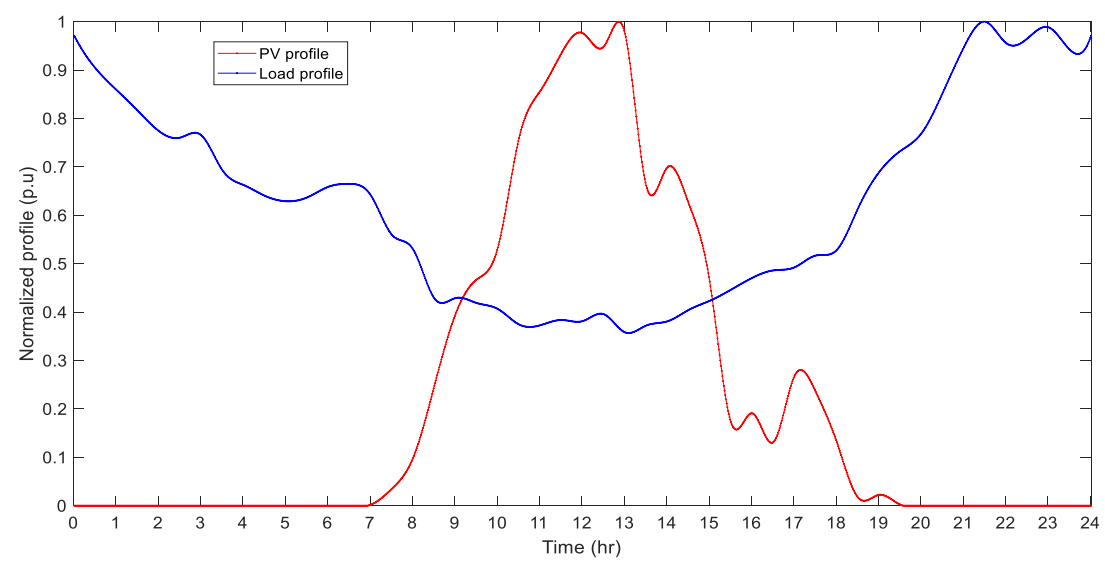

Figure 4. Normalized PV profile and residential load profile 
It was assumed that all customers are connected with PV systems equipped with smart inverters and share the same irradiance profile. The size of a PV panel was varied in the range of $2-7 \mathrm{kWp}$ (until the total PV capacity connected to the network reaches within $90 \%$ of the transformer capacity). The performance of two different Vol/Var curves were investigated by adopting typical and oversized smart PV inverters to mitigate overvoltage issues due to high integration of solar PV. The curves were defined considering two possible combinations of active-bands and dead-bands as shown in Figure 5. In both curves, V2 and V5 voltages (Figure 1) were set as the lower and upper voltage statutory limits. It was assumed that all PV inverters in the LVDN share the same Volt/Var set points.

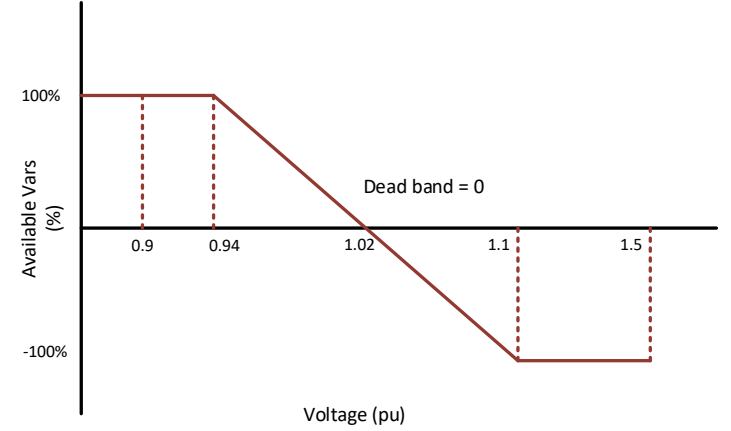

(a)

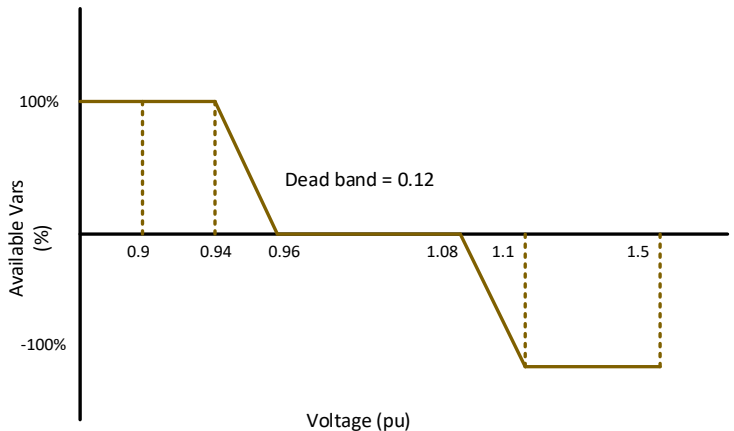

(b)

Figure 5. Volt/var curves, (a) VV1: without dead band, (b) VV2: with dead band

\section{RESULTS AND DISCUSSION}

Time series, three-phase power flow simulations were performed for six PV penetration levels ( $40 \%$ to $140 \%$ in steps of $20 \%$ ) and voltage profiles of all customers were obtained and examined before and after the Volt/Var control. According to the simulation results, no customers were experiencing voltage violations upto $80 \%$ of penetration level without any voltage control. However, for a further increment in penetration level, 2, 44 and 68 number of customers were recorded with voltage violations for 100\%, $120 \%$ and $140 \%$ of penetration levels respectively. Figure 6 shows the uncontrolled daily voltage profiles of all 124 customer nodes with 7kWp PV installations (140\% of PV penetration level).

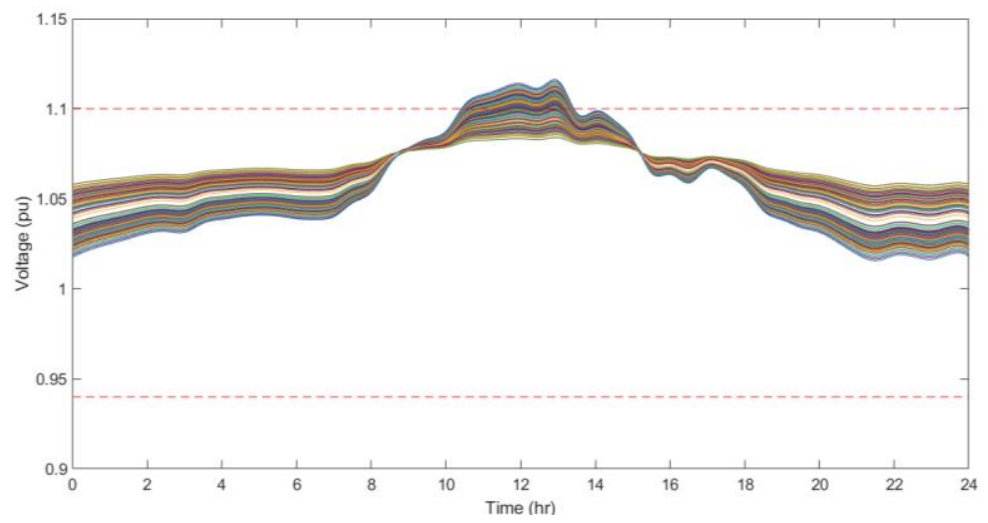

Figure 6. Uncontrolled daily voltage profiles of all customers in the LVDN with 7kWp PV installations

Figures 7 and 8 display the voltage profiles and daily reactive power compensation for both Volt/Var curves, obtained by utilizing typical and oversized smart PV inverters. In each graph, the corresponding parameter variation is demonstrated for all 124 customers. The voltage profiles obtained for VV1 and VV2 Volt/Var set points with typical PV inverter (for 140\% of PV penetration) are shown in Figures 7(a) and 7(b) respectively. Although a voltage reduction was observed during non-peak generation, the voltage profiles persist nearly the same during peak generation. As a result, the number of customers with voltage issues was also remained the same similar to the uncontrolled mode. 


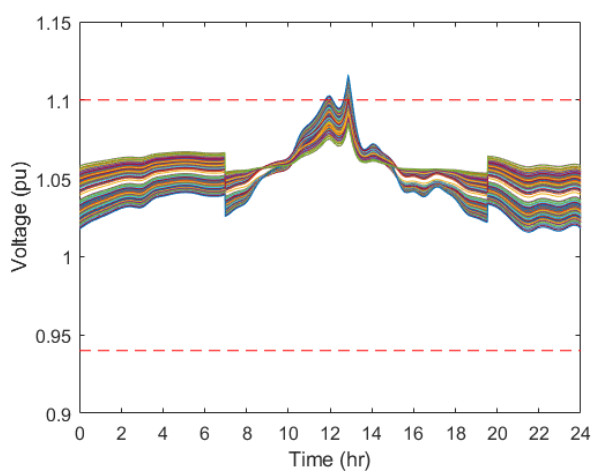

(a)

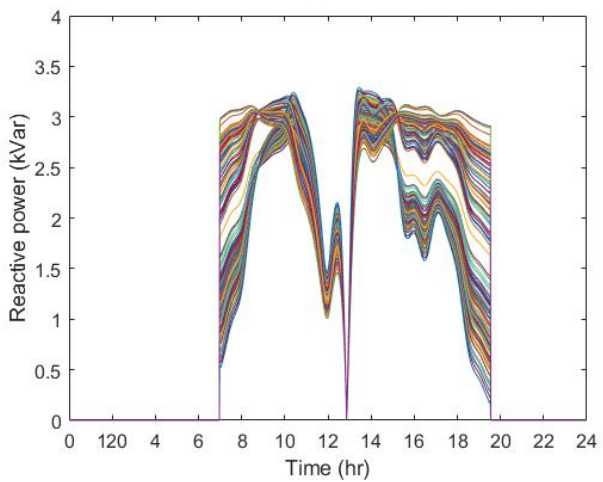

(c)

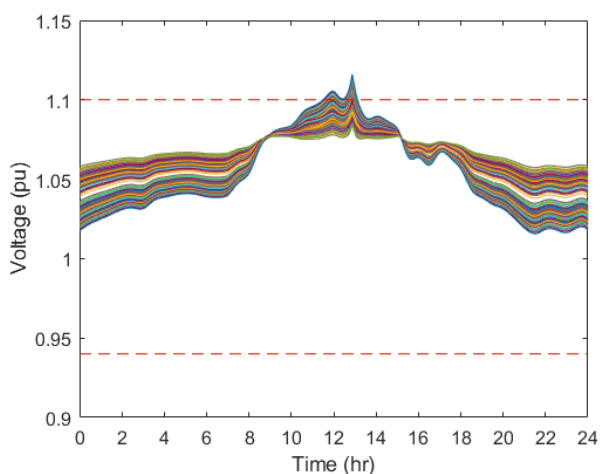

(b)

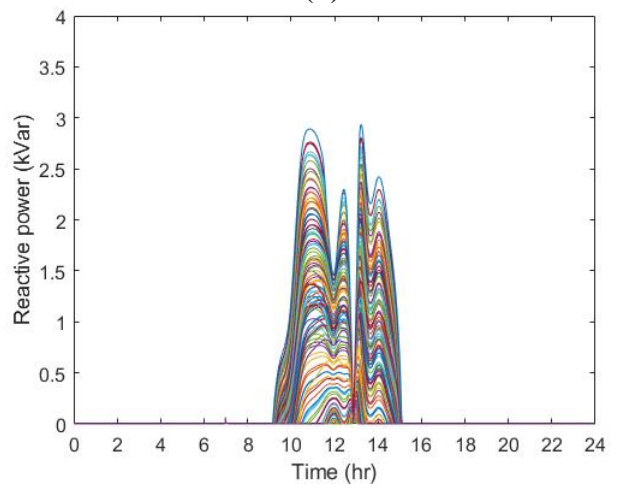

(d)

Figure 7. Daily voltage profiles of customers and reactive power compensation of all PV systems, (a) and (c) for VV1, (b) and (d) for VV2 volt/var set points using typical smart PV inverter

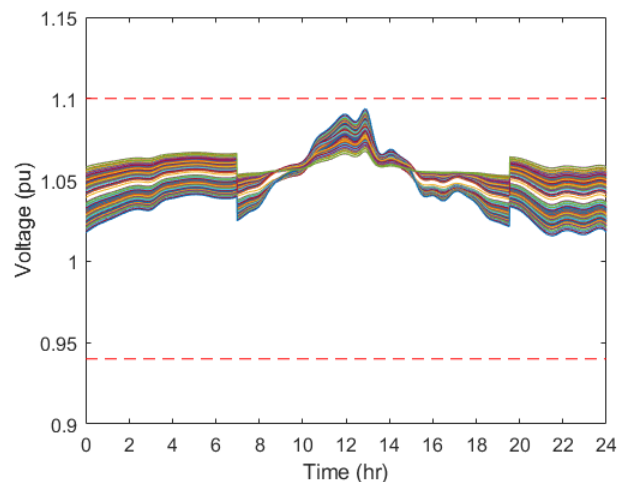

(a)

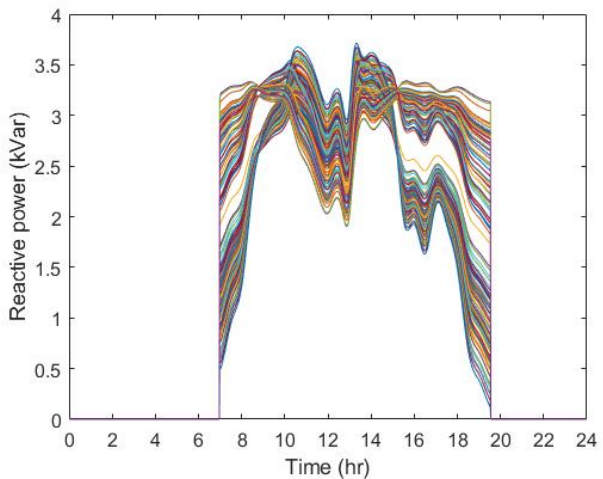

(c)

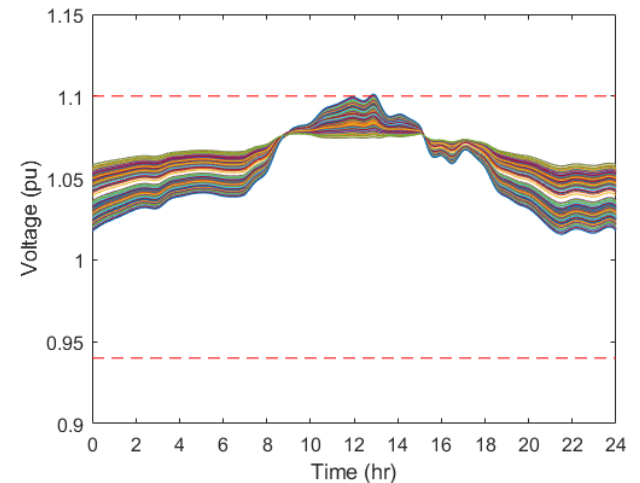

(b)

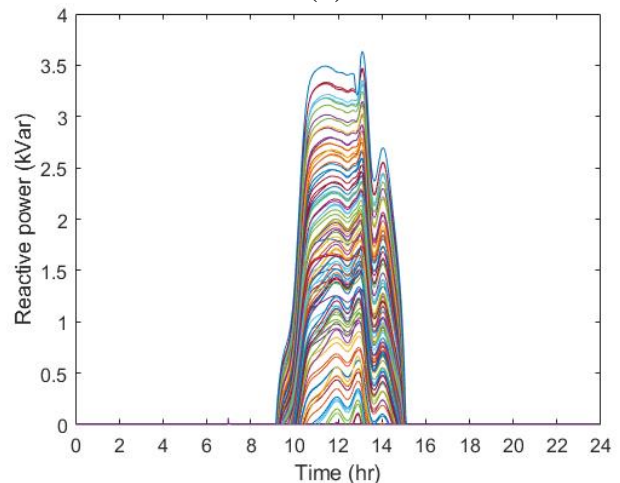

(d)

Figure 8. Daily voltage profiles of customers and reactive power compensation of all PV systems, (a) and (c) for VV1, (b) and (d) for VV2 Volt/Var set points using oversized smart PV inverter 
In fact, Figures 7(c) and 7(d) which illustrate the daily reactive power compensation of all PV installations, clearly depict that this is due to the limited reactive power capability of typical PV inverter during peak active power generation. The adoptation of oversized PV inverter could be introduced as a feasible solution to overwhelm this issue. As clearly depicted in Figures 8(a) and 8(b), the voltage has been significantly reduced for both VV1 and VV2 set points. The daily reactive power absorption for the two set points are shown in Figures 8(c) and 8(d). It could be seen that the spare capacity of oversized inverter facilitates the reactive power support during high active power generation. According to the simulation results, the customers with voltage issues has shown a rapid drop after adopting oversized PV inverters. No customers were recorded with voltage violations for VV1 set points while only three customers were recorded for VV2 set points. It was revealed that the performance of Volt/Var control could be enhanced by adopting sensitive set points/curves with shorter deadbands which allow higher reactive power support during high influx of solar PV to the LVDN.

\section{CONCLUSION}

This paper presents the performance of Volt/Var control of smart PV inverters in mitigating overvoltage issues due to high integration of solar PV to the LVDNs. A comprehensive analysis has been conducted on a real Malaysian LVDN considering two different Volt/Var set points under different PV penetration levels. The results showed that typical PV inverters of the same size as the PV panels are unable provide an adequate voltage regulation using Volt/Var control due to the priority given to real power generation and limited reactive power capability during peak irradiance. This problem was found to be alleviated by the use of an oversized PV inverter as it effectively controls the voltage by enhancing its reactive power capability while delivering the peak power generation. Further it is proposed to adopt sensitive Volt/Var set points/curves with shorter deadbands to increase the PV hosting capacity of LVDNs.

\section{ACKNOWLEDGEMENTS}

The authors would like to thank the Tenaga Nasional Berhad (TNB), Malaysia, for funding this research under a TNB R\&D Seeding Fund (U-TD-RD-19-07) and UNITEN R\&D Sdn. Bhd.

\section{REFERENCES}

[1] M. Karimi, et al., "Photovoltaic penetration issues and impacts in distribution network - A review," Renewable and Sustainable Energy Reviews, vol. 53, pp. 594-605, 2016.

[2] T. Aziz and N. Ketjoy, "PV Penetration Limits in Low Voltage Networks and Voltage Variations," IEEE Access, vol. 5, pp. 16784-16792, 2017.

[3] R. Tonkoski, et al., "Impact of high PV penetration on voltage profiles in residential neighborhoods," IEEE Transactions on Sustainable Energy, vol. 3, no. 3, pp. 518-527, 2012.

[4] K. A. Alboaouh and S. Mohagheghi, "Impact of Rooftop Photovoltaics on the Distribution System," Journal of Renewable Energy, vol. 2020, pp. 1-23, 2020.

[5] A. Navarro-Espinosa and L. F. Ochoa, "Increasing the PV hosting capacity of LV networks: OLTC-fitted transformers vs. reinforcements," 2015 IEEE Power \& Energy Society Innovative Smart Grid Technologies Conference (ISGT), Washington, DC, pp. 1-5, 2015.

[6] T. Stetz, et al., "Techno-economic assessment of voltage control strategies in low voltage grids," IEEE Transactions on Smart Grid, vol. 5, no. 4, pp. 2125-2132, 2014.

[7] Y. P. Agalgaonkar, et al., "Distribution voltage control considering the impact of PV generation on tap changers and autonomous regulators," IEEE Transactions on Power Systems, vol. 29, no. 1, pp. 182-192, 2014.

[8] M. Y. Suliman, "Voltage profile enhancement in distribution network using static synchronous compensator STATCOM," International Journal of Electrical and Computer Engineering (IJECE), vol. 10, no. 4, pp. 3367-3374, 2020.

[9] H. F. Kadom, et al., "Dual technique of reconfiguration and capacitor placement for distribution system," International Journal of Electrical and Computer Engineering, vol. 10, no. 1, pp. 80-90, 2020.

[10] P. Chaudhary and M. Rizwan, "Voltage regulation mitigation techniques in distribution system with high PV penetration: A review," Renewable and Sustainable Energy Reviews, vol. 82, no. 3, pp. 3279-3287, 2018.

[11] M. R. B. Khan, et al., "Energy management system for PV-battery microgrid based on model predictive control," Indonesian Journal of Electrical Engineering and Computer Science, vol. 15, no. 1, pp. 20-25, 2019.

[12] IEEE Standard Association, "Standard for Interconnection and Interoperability of Distributed Energy Resources with Associated Electric Power Systems Interfaces," IEEE Std. 1547-2018 (Revision of IEEE Std 1547-2003), pp. 1-138, 2018.

[13] R. Tonkoski and L. A. C. Lopes, "Impact of active power curtailment on overvoltage prevention and energy production of PV inverters connected to low voltage residential feeders," Renewable Energy, vol. 36, no. 12, pp. 3566-3574, 2011.

[14] R. Tonkoski, et al., "Droop-based active power curtailment for overvoltage prevention in grid connected PV inverters," IEEE International Symposium on Industrial Electronics, pp. 2388-2393, 2010. 
[15] J. Seuss, et al., "Improving distribution network PV hosting capacity via smart inverter reactive power support," IEEE Power and Energy Society General Meeting, pp. 1-5, 2015.

[16] K. Turitsyn, et al., "Options for control of reactive power by distributed photovoltaic generators," Proceedings of the IEEE, vol. 99, no. 6, pp. 1063-1073, 2011.

[17] E. Demirok, et al., "Local reactive power control methods for overvoltage prevention of distributed solar inverters in low-voltage grids," IEEE Journal of Photovoltaics, vol. 1, no. 2, pp. 174-182, 2011.

[18] Meghasai, et al., "Simulation of smart functionalities of photovoltaic inverters by interfacing OpenDSS and Matlab," 2015 IEEE 16th Workshop on Control and Modeling for Power Electronics (COMPEL), Vancouver, BC, pp. 1-6, 2015.

[19] M. J. Reno, et al., "Smart inverter capabilities for mitigating over-voltage on distribution systems with high penetrations of PV," Conference Record of the IEEE Photovoltaic Specialists Conference, pp. 3153-3158, 2013.

[20] T. S. Ustun, et al., "Impact of Smart Inverters on Feeder Hosting Capacity of Distribution Networks," IEEE Access, vol. 7, pp. 163526-163536, 2019.

[21] J. W. Smith, et al., "Smart inverter volt/var control functions for high penetration of PV on distribution systems," 2011 IEEE/PES Power Systems Conference and Exposition, PSCE 2011, pp. 1-6, 2011.

[22] M. J. Parajeles, et al., "Assessing the performance of smart inverters in large-scale distribution networks with PV systems," 2017 IEEE PES Innovative Smart Grid Technologies Conference - Latin America, ISGT Latin America, pp. 1-6, 2017.

[23] B. Bletterie, et al., "Voltage Control with PV Inverters in Low Voltage Networks-In Depth Analysis of Different Concepts and Parameterization Criteria," IEEE Transactions on Power Systems, vol. 32, no. 1, pp. 177-185, 2017.

[24] W. Moondee and W. Srirattanawichaikul, "Study of Coordinated Reactive Power Control for Distribution Grid Voltage Regulation with Photovoltaic Systems," 2019 IEEE PES GTD Grand International Conference and Exposition Asia (GTD Asia), pp. 136-141, 2019.

[25] J. F. Gómez-González, et al., "Reactive power management in photovoltaic installations connected to low-voltage grids to avoid active power curtailment," Renewable Energy and Power Quality Journal, vol. 1, no. 16, pp. 5-11, 2018.

[26] W. Sunderman, et al., "Open source modeling of advanced inverter functions for solar photovoltaic installations," in Proceedings of the IEEE Power Engineering Society Transmission and Distribution Conference and Exposition, pp. 1-5, 2014.

\section{BIOGRAPHIES OF AUTHORS}

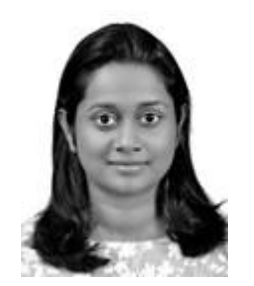

Dilini Almeida received the B.Sc.Eng. Degree in Electrical and Electronic Engineering from the University of Peradeniya, Sri Lanka, in 2017. She is currently working as a graduate research officer at Institute of Sustainable Energy and pursuing her M.Sc. degree in electrical engineering at Universiti Tenaga Nasional, Malaysia. Her main research interests include power system analysis and renewable energy integration.

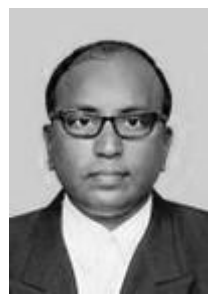

Dr. Jagadeesh Pasupuleti is the Head of Hybrid Renewable Energy Systems, Institute of Sustainable Energy, Universiti Tenaga Nasional, Malaysia. He is a Senior Member of IEEE (USA), Member of IET (UK), Chartered Engineer (UK), Professional Review Interviewer for CEng (UK), Member of EI (UK), Member of BEM (Malaysia) and Member of ISTE (India). He has 32 years of teaching, research and administrative experience. He has supervised 30 postgraduate students, published 100 papers and involved in 40 research and consultancy projects funded around $\$ 2$ million in renewable energy. His research interests include power system, hybrid renewable energy systems, smart grid, energy efficiency, electricity markets and demand side response.

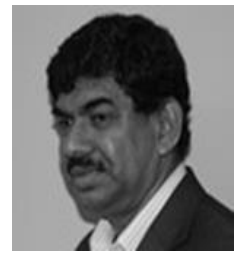

Prof. Janaka B. Ekanayake received the B.Sc. degree in electrical engineering from the University of Peradeniya, Peradeniya, Sri Lanka, in 1990, and the Ph.D. degree in electrical engineering from the University of Manchester Institute of Science and Technology, Manchester, U.K., in 1995. He joined the University of Peradeniya, as a Lecturer, where he was promoted to a Professor of Electrical Engineering in 2003. In 2008, he joined the Cardiff School of Engineering, Cardiff, U.K. He is currently with the University of Peradeniya and Cardiff University, Cardiff. His current research interests include power electronic applications for power systems, renewable energy generation, and its integration and smart grid applications.

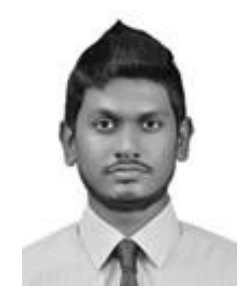

Eshan Karunarathne received the B.Sc.Eng. Degree in Electrical and Electronic Engineering from the University of Peradeniya, Sri Lanka, in 2017. He was a research assistant at School of Aerospace, Transport and Manufacturing, University of Cranfield, The United Kingdom. He is currently working as a graduate research officer at Institute of Sustainable Energy and pursuing his M.Sc. degree in electrical engineering at Universiti Tenaga Nasional, Malaysia. His main research interests include power system analysis, renewable energy integration and grid connected power electronic devices. 